\title{
Coble and Eisenhart: Two Gettysburgians Who Led Mathematics
}

\author{
Darren B. Glass
}

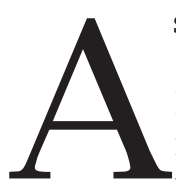

s of 2012, sixty-one people had held the office of president of the American Mathematical Society. Of these fiftynine men and two women, ten received undergraduate degrees from Harvard. Another five received their undergraduate degrees from Columbia University. Five schools have had three alumni apiece go on to serve as AMS president, and none of the schools on this list would surprise anyone-Princeton, Yale, Cambridge, Texas, and Chicago have all been centers of mathematics at various times. Three more schools have had two alumni each become AMS president: MIT, Wesleyan University, and Gettysburg College. Yes, there have been more Gettysburg College alumni to serve as AMS president than many schools whose math programs are far more renowned.

The story is even more interesting when one notes that the two Gettysburg College alumni served as back-to-back presidents of the AMS, with Luther Pfahler Eisenhart serving in 1931-1932 and Arthur Byron Coble serving in 1933-1934. Furthermore, they graduated from Gettysburg, then known as Pennsylvania College, a year apart, with Eisenhart one of the sixteen members of the class of 1896 and Coble one of the twenty-six members of the class of 1897. In other words, of the 134 students who were attending Gettysburg College in 1895, two of them would receive Ph.D.'s in mathematics from Johns Hopkins and go on to be the president of one of the most important academic societies in the world. In this article, we take a closer look at this coincidence.

Darren B. Glass is professor of mathematics at Gettysburg College. His email address is dg1 ass@gettysburg.edu.

DOI: http://dx.doi.org/10.1090/noti991

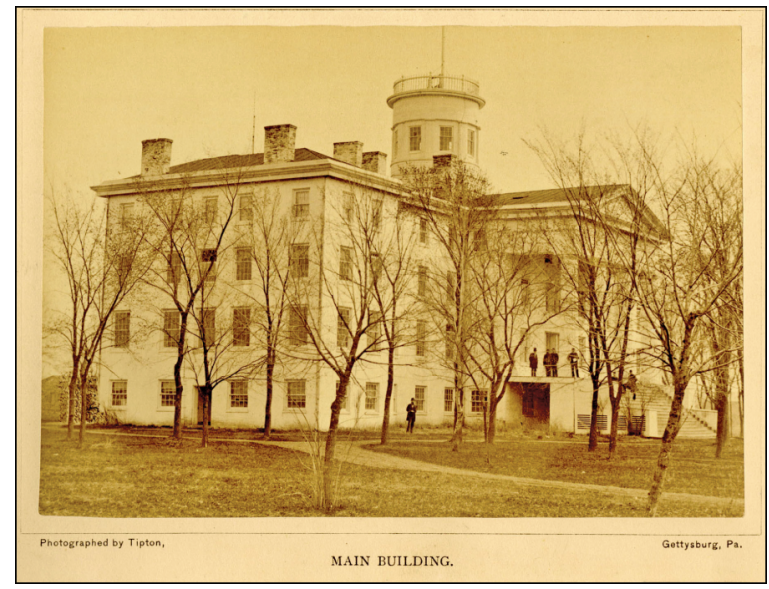

Pennsylvania College circa 1890.

\section{Mathematics at Gettysburg}

The end of the nineteenth century was a time of change in the world of higher education in general and mathematics in particular. In their book A History of Mathematics in America before 1900 [26], Smith and Ginsburg write that "from 1875 to 1900 a change took place that may well be described as little less than revolutionary. Mathematics tended to become a subject per se; it became 'pure' mathematics instead of a minor topic taught with astronomy and physics as its prime objective." Much of this revolution was occurring at the newly founded Johns Hopkins University, which was the first American university to offer graduate programs in mathematics and featured the prominent mathematicians J. J. Sylvester and Arthur Cayley on its faculty. ${ }^{1}$

\footnotetext{
${ }^{1}$ For more information on mathematics at Johns Hopkins and in the United States more generally in this era, the
} 


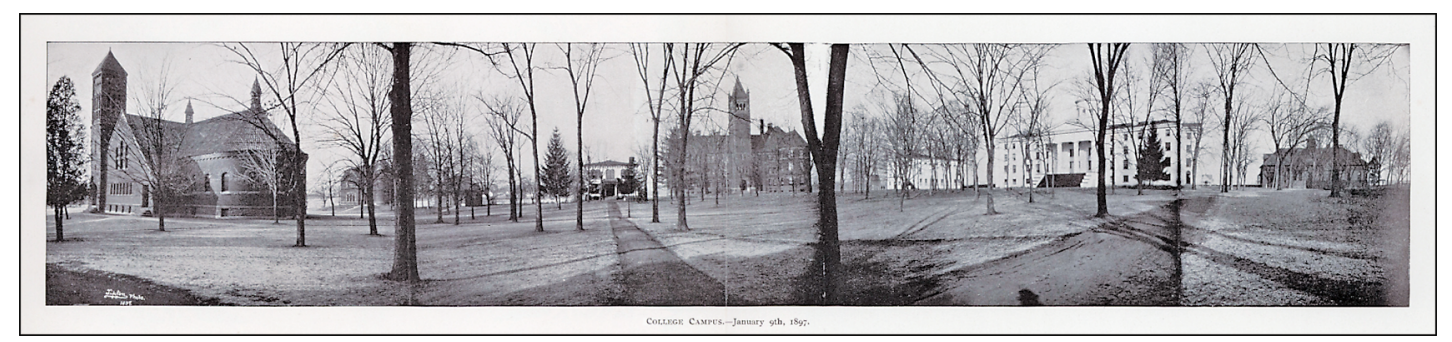

Panorama of Pennsylvania College, 1897.

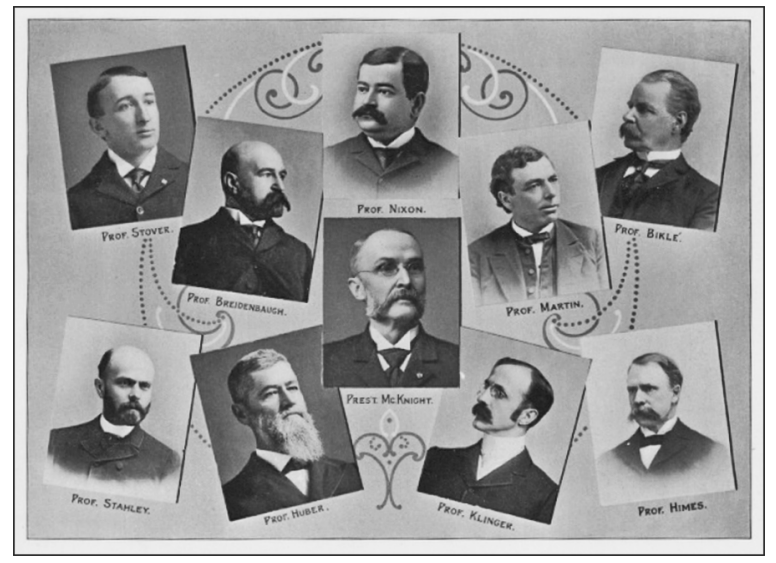

Pennsylvania College Faculty, 1898.

One of the earliest graduate students in mathematics at Johns Hopkins was Henry B. Nixon, who received his Ph.D. in 1886 with a dissertation entitled "On Lamé's Equation". Nixon was born in North Carolina in 1857 and earned a bachelor's degree from the University of North Carolina in 1878. While a graduate student at Hopkins, he coauthored the Bibliography of Linear Differential Equations with J. W. Fields [24], the initiator of the Fields Medal. Nixon began teaching at Pennsylvania College in 1888 when the college's previous professor of mathematics, Luther Croll, fell ill. Pennsylvania College had been founded in the town of Gettysburg by the Lutheran theologian Samuel Simon Schmucker in 1832 and changed its name to Gettysburg College in 1921.

According to Charles Glatfelter's history of Gettysburg College, entitled A Salutary Influence [16], Nixon was one of only four faculty members hired between 1868 and 1904 who had a doctorate degree. As was typical of schools of its kind in the late nineteenth century, the curriculum of the college was highly regimented, with all students pursuing either the Classical Course or the Scientific Course. Prior to 1890 one's course determined all classes one would take at the

author recommends the book The Emergence of the American Mathematical Research Community, 1876-1900 by Parshall and Rowe [25]. college. Students in either course were expected to enter the college knowing "Arithmetic complete, including the Metric System; Elementary Algebra; Geometry to Book III (Wentworth's)" [1]. The catalog described the college's program in mathematics thusly:

The instruction in the department of Mathematics is conveyed by the constant and systematic study of approved textbooks, interspersed with familiar lectures; the student being assisted by full and frequent explanations from the Professor, and being constantly subjected to rigid examinations. The progress of every student is also tested by his being required to perform miscellaneous exercises, in which the principles acquired are applied to the solution of particular problems.

More precisely, the coursework in mathematics expected of all students at Pennsylvania College was described as follows:

\begin{tabular}{|l|l|l|}
\hline Freshman Year & $\begin{array}{l}\text { First Term } \\
\text { Second Term }\end{array}$ & $\begin{array}{l}\text { Geometry (Wentworth) 4 } \\
\text { Geometry of Planes (Wentworth); } \\
\text { Algebra (Wentworth) 4 } \\
\text { Algebra (Wentworth), } \\
\text { Plane Trigonometry (Wentworth) 4 }\end{array}$ \\
\hline Sophomore Year & $\begin{array}{l}\text { First Term } \\
\text { Second Term } \\
\text { Third Term }\end{array}$ & $\begin{array}{l}\text { Plane Trigonometry and } \\
\text { Mensuration (Wentworth) 3 } \\
\text { Analytical Geometry (Newcomb) 3 } \\
\text { Analytical Geometry (Newcomb), } \\
\text { Spherical Trigonometry (Wentworth), } \\
\text { Surveying and Navigation (Wentworth) 3 }\end{array}$ \\
\hline Junior Year & $\begin{array}{l}\text { First Term } \\
\text { Second Term } \\
\text { Third Term }\end{array}$ & $\begin{array}{l}\text { Differential Calculus (Newcomb) 2, } \\
\text { Integral Calculus (Newcomb) 2 } \\
\text { None }\end{array}$ \\
\hline Senior Year & \multicolumn{2}{|l|}{ None } \\
\hline
\end{tabular}

A modern reader looking at this list of courses is likely to be surprised by how elementary the coursework was, with no students taking material past the Integral Calculus, a subject that many students a hundred years later would complete by the end of their first year at college. It is worth pointing out that Pennsylvania College was not unusual in this respect at that time, as a consideration of mathematics curricula at some other small colleges in the region will show. 
Students at Swarthmore College had four courses of study to choose from, but all four required very similar mathematics requirements to students at Pennsylvania College [4]. The curricula of Williams College was also similar [28].

As Smith and Ginsburg noted, "It will therefore be observed that the work in the freshman year of college was, in the first half of the century, merely that of a mediocre high school of the twentieth century, a fact which testifies to the poor work done in the field of mathematics in the preparatory schools of the time" [26, p. 72]. Moreover, at most colleges the mathematics program culminated in courses on astronomy and navigation, indicating that the pure mathematics revolution discussed earlier had not yet trickled down to undergraduate curricula. Gettysburg College was also introducing elective courses into the curriculum in the last decade of the nineteenth century, and one of the first electives officially on the books was a mathematics course that included "Analytic Geometry of three dimensions; differential equations; Mechanics" [3]. The faculty and trustees felt that the curriculum was not as robust as they would like and added a section to the Gettysburg College catalogue in 1891: "Called 'Needs of the College', it listed five so-called departments in which additional 'teaching force and apparatus' were required...it is a stark commentary on the fate of the College during the next thirteen years to observe that the very same notice.... appeared in the 1904 catalogue" [16, p. 296]. It was not until 1915 that Gettysburg would hire additional faculty in mathematics.

\section{Eisenhart}

Luther Pfahler Eisenhart was born to Charles Augustus Eisenhart and Emma Catherine Pfahler on January 13, 1876, in York, Pennsylvania. Charles Eisenhart's primary occupation was as a dentist, but Luther himself wrote of his father that dentistry may have "made sufficient income to meet the expenses of his growing family, but his intellect was too active to be satisfied by dentistry. Electricity appealed to him and he organized the Edison Electric Light Company in the early eighties. The telephone also made an appeal. He experimented with telephones and in the late nineties organized the York Telephone Company" [21]. He also patented a method of using electricity to supersede the use of anesthetics in extracting and filling teeth, which made him one of the most prominent dentists in Pennsylvania [15]. Charles's mother was Elizabeth Schmucker, whose brother was Samuel Simon Schmucker, the Lutheran pastor and theologian who founded the Lutheran Theological Seminary in Gettysburg as well as Pennsylvania College.
Luther was the second of six sons, and he showed great intelligence from an early age. Under his mother's tutoring, he finished his primary schooling in three years instead of the standard six. In September 1892 he enrolled at Pennsylvania College and was active in all aspects of college life. The Spectrum, the yearbook of Gettysburg College, lists Eisenhart as a member of the Philomathean Literary Society and the Phi Kappa Psi fraternity, the recording secretary of the Athletic Association, and the captain of the baseball team, for which he played third base. Luther was awarded the Muhlenberg Freshman Prize and the following year tied with another student for the Baum Prize, which is "given to the student showing the greatest proficiency in mathematics through his or her sophomore year." He earned honorable mention for the Hassler Medal in Latin and won the Graeff Prize in English. The catalog also lists him as one of four students to receive "First Honors" upon graduation, and he delivered the valedictory for the class of 1896.

After graduation Eisenhart continued to live in Gettysburg. He spent a year as a "Tutor in Mathematics and Natural Science", living in Stevens Hall and working with the students at the Gettysburg Academy, a preparatory school. Following this year, Luther went to Johns Hopkins, where three years later he received a doctoral degree for writing a dissertation entitled "Infinitesimal Deformation of Surfaces". In the fall of 1900, Eisenhart was appointed as an instructor of mathematics at Princeton University, a position that earned $\$ 800$ per year, and five years later he was accorded the rank of assistant professor when Woodrow Wilson, then president of the university, began the preceptorship program. In 1908 Eisenhart married Anna Maria Dandridge Mitchell, and they had a son, Churchill, in 1913. Churchill went on to become a prominent statistician in his own right, holding the position of chief of the Statistical Engineering Laboratory at the National Bureau of Standards from 1947 until 1963. Anna died shortly after the birth of their son, and Luther married Katharine Schmidt five years later. Luther and Katharine eventually had two daughters together.

In 1925 Luther Eisenhart became dean of the faculty at Princeton, and Katharine took it upon herself to socialize the wives of graduate students. One student recalls that "she took that job seriously...she wanted these girls to learn how to be faculty wives, to know all the correct social procedures. She not only had regular meetings, talking with them, but she also arranged for them to visit prominent homes...where they could practice the social graces" [2, Mood].

Through all of these positions Eisenhart was a model faculty member, excelling in all three of 
the traditional areas of research, teaching, and governance. During his career, Eisenhart published nearly one hundred papers and a half dozen books in addition to supervising seven doctoral students. There were two main themes to his scholarly work, although it all falls into the category of differential geometry. Early in his career Eisenhart looked at deformations of surfaces, continuing the work he had done in his dissertation. In particular, he was interested in understanding global properties of manifolds by looking at their local structure. Eisenhart's first book was a graduate-level textbook entitled A Treatise in the Differential Geometry of Curves and Surfaces [14], originally published in 1909. This book grew out of courses that he had taught at Princeton and covered aspects of the field that were considered classical at the time as well as more modern topics. In particular, the book contained sections on twisted curves and surfaces, ruled surfaces, minimal surfaces, deformations, and triply orthogonal systems of surfaces. Several reviews lauded the book for its discussion of "moving trihedrals", a subject about which one reviewer said, "The student will hardly find himself at home in the literature of to-day without an intelligent acquaintance with them." While Eisenhart's book was not the first textbook on the subject published in America, it was very influential. Archibald writes that "the work was of great value in introducing the American student to an important field by the most modern method of the time" [5].

Eisenhart published a research monograph entitled Transformations of Surfaces in 1923. The aim of this book was to consider surfaces in $\mathbb{R}^{3}$ and various transformations, which can be put into two categories, $F$-transformations and $W$-transformations, depending on how they act on certain nets. Eisenhart's book summarized work done by others, including Bianchi, Darboux, Guichard, Ribaucour, and Tzitzeica, while further developing it as well. A review in the Bulletin of the AMS says that "to unify such a diversity of material in a natural and effective fashion is not simple, and the author is to be congratulated on the masterly way in which he has succeeded" [19].

Around this time, Eisenhart's scholarly thoughts were becoming increasingly influenced by the work of Albert Einstein on general relativity. In particular, Riemann's work on the generalization of surfaces to spaces of higher orders and Ricci's subsequent work on the tensor analysis and absolute calculus applied very well to the types of forms that turned up in Einstein's models. Inspired by this work, he wrote two books, Riemannian Geometry [13] and Non-Riemannian Geometry [12], the latter of which was based on his series of lectures in the AMS Colloquium Series. As with his other books,

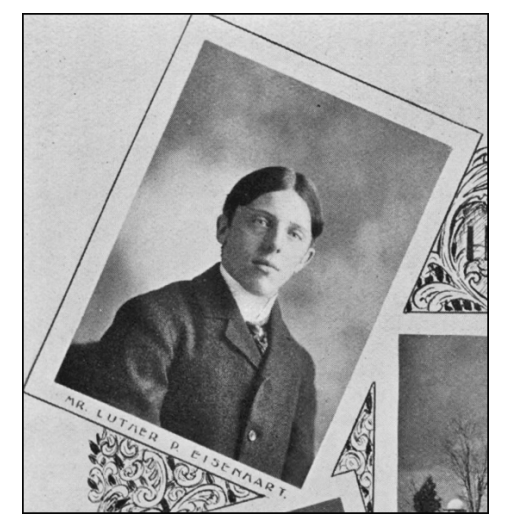

Luther Eisenhart as instructor at Gettysburg Academy.

these became standard references in the field. Eisenhart wrote two more books, one of which was a treatise on Lie algebras, which were originally a tool developed in the study of Riemannian geometry but which had become an object of study in their own right by the time he wrote Continuous Groups of Transformations [11]. His final book was another textbook published in 1940, entitled An Introduction to Differential Geometry [14], which expanded on his earlier textbook to include the innovations in the field over the previous three decades.

In addition to his scholarly work, Luther Eisenhart loved teaching and insisted on teaching courses every term during the forty-five years he spent at Princeton without a single sabbatical. His son, Churchill, recalls that "Dad wanted to teach a freshman course even when he became Dean of the Graduate College in order to get a feel for what the new generation of students was like. He felt it important to keep your hand on that pulse. And he was very much against the idea of what you might call a research mathematician who doesn't do any ordinary teaching" [2, C. Eisenhart]. His teaching was based on the philosophy that "teaching methods must be designed to encourage independence and self-reliance, to evoke curiosity, and stimulate the imagination and creative impulse" [22]. He emphasized classroom discussion, and classes were often held with a student at the blackboard. Joseph Daly said that "he could get the guys so aggravated that they had to try to prove examples, but I also got some other things out of it. I began to think of mathematical philosophy, with a mathematical formulation of course, the Descartes sort of thing" [2, Singleton].

Eisenhart had strong opinions on teaching and curricular matters, many of which can be directly attributed to his experiences at Gettysburg College. He believed that the purpose of education was to teach students how to teach themselves. In his 


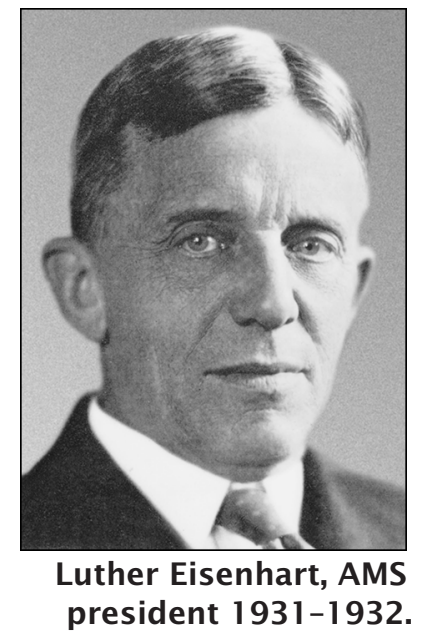

obituary of Eisenhart, Lefschetz quotes him on the subject:

Henry B. Nixon gave me books to study and report when I had any questions; there were no class sessions. The same plan on a more extensive basis was followed in senior year. This experience with the value of independent study led to my proposal in 1922 that the undergraduate curriculum for juniors and seniors in Princeton should provide for independent study, which was adopted and has continued. [21]

The above proposal he refers to was called "The Four-Course Plan". While students had traditionally taken five courses at a time, they would now take only four courses, typically two in a major field and two other courses that would now be considered general education. Additionally, all students would take independent studies with faculty, culminating in a mandatory senior thesis. When it was first introduced, this curriculum was quite controversial. Faculty feared that it would be too much work for them, alumni worried that it would hurt the chances of the football team, and students had concerns that it would be too much work. Several seniors composed a verse that described their attitudes about this curriculum, singing, "Luther Pfahler Eisenhart, efficient from the very start; But he's condemned in the eyes of man for originating the four-course plan." In fact, the opposition was strong enough that a committee was appointed to investigate. In the end, Eisenhart was able to give evidence that the new curriculum was beneficial to students' experiences. Eventually, the ideas of majors and senior theses gained wide acceptance, with many schools adopting similar curricula.

Several new programs were established at Princeton under Eisenhart's watch, including the Near East studies program. Many people give him credit for starting the statistics program, as it was during his tenure at Princeton that the first probability courses were taught and also that the first statistician, Sam Wilks, was hired. This latter decision was controversial within the program, with much of the mathematics faculty not believing that statistics belonged in a mathematics department and many of the social scientists on campus agreeing. Eisenhart also helped to build several programs outside the mathematics department.

Eisenhart was also a significant contributor to both the mathematical community and the world of higher education more generally. In addition to serving as the president of the American Mathematical Society, he spent time as president of the American Association of Colleges, as vicepresident of the National Academy of Sciences and of the American Association for the Advancement of Science. He also served as one of the founding members of the Middle States Commission on Institutes of Higher Education beginning in 1919.

In addition to the many ways in which he served his profession, Eisenhart also had several opportunities to serve his country. In 1940 he chaired a joint committee of the National Academy of Sciences and the National Research Council tasked with developing policies for dealing with scientific publications that might have military applications. Twice Eisenhart was asked to sit on committees established by the National Academy of Sciences to give reports to Congress about congressional apportionment, ${ }^{2}$ including one that he chaired.

Eisenhart was serving as both the dean and head of the mathematics department at Princeton when the Institute for Advanced Study (IAS), a think tank also located in Princeton, New Jersey, was founded. The fact that the institute's first "school" was in mathematics served as both a fortuitous opportunity for Princeton's math department and a potential risk. On one hand, it would bring some of the greatest mathematical minds of the time to Princeton in order to do mathematics. On the other hand, the institute was recruiting faculty from Princeton's ranks, as it was easier to recruit faculty who would not have to move to a different town, let alone a different country. As dean, it was incumbent upon Eisenhart to navigate these political waters in an effort to help the two institutions thrive rather than hurt one another. Luckily, Eisenhart and IAS founder Abraham Flexner got along well and worked together to help improve both institutions, although they often would pursue the same people to join their faculty ranks. One example was John von Neumann, who eventually chose to be employed at the IAS despite a prior commitment to Princeton. Eisenhart had good reasons for allowing this to happen, but it alienated many trustees, and some observers have suspected that it cost him the presidency of Princeton. ${ }^{3}$

\footnotetext{
${ }^{2}$ The Constitution of the United States specifies that each state should receive proportional representation in Congress but is surprisingly vague on how many members the House of Representatives should have and how they should be divided among the states. The author would refer the interested reader to Szpiro's book Numbers Rule: The Vexing Mathematics of Democracy, from Plato to the Present [27]. ${ }^{3}$ Batterson discusses all of these political wranglings in his account of the founding of the IAS, entitled Pursuit of Genius: Flexner, Einstein, and the Early Faculty at the Institute for Advanced Study [6].
} 
Eisenhart also got into a sticky political situation related to the International Congress of Mathematicians. Traditionally, the location of the ICM is decided after a country's professional association of mathematicians extends an invitation. Eisenhart, along with L. E. Dickson, invited the congress to meet in New York City in 1924 without the official backing of the American Mathematical Society. This was particularly controversial, as the United States and Great Britain had been excluded from the 1920 Congress in Strasbourg, and in the end the congress was moved to Toronto. ${ }^{4}$ It was therefore especially significant that it was Eisenhart who in 1936 again invited the International Congress to be held in the United States, emphasizing that "mathematics is international...it does not recognize national boundaries."

Despite the fact that his true professional interests always seemed to be teaching and research, Eisenhart viewed these administrative responsibilities as something that should be done without complaining. When asked whether his father enjoyed administrative work, his son Churchill Eisenhart responded that "I think it was a thing that he felt should be done, and he didn't let it interrupt him very much... To give you an illustration, I don't know what year this was, but the mathematical society was meeting somewhere. Dad said to his wife, 'Katy, I'll have to be gone the next couple days, because I have to go to the mathematical meeting.' 'Oh, Luty,' she said, 'you know you really need a rest,' and so forth. 'Why don't you take a few days off?' He said, 'I can't. I'm the president. I have to give a talk.' That was the first time that she knew he was the president" [2, C. Eisenhart]. He was greatly respected as an administrator for his no-nonsense attitude. Another rhyme that the students composed about him discussed the showers that he had installed in Fine Hall: "Here's to Eisenhart, Luther Pfahler / At Mathematics, he's a whaler / He's built a country club for math / Where you can even take a bath."

Throughout his life, Eisenhart remained connected to Gettysburg College. He became a trustee of the college in 1907, and early in his time as a trustee served on a committee that looked at the admissions standards of the college in an attempt to raise them in response to a report expressing concerns that the college was not meeting national standards for higher education. In 1910 Gettysburg College was looking for a new president, and Eisenhart's name was one of the top choices; in particular, polls of the various alumni clubs throughout the country regularly listed him as

\footnotetext{
${ }^{4}$ For details, the author refers the reader to Curbera's history of the ICM, entitled Mathematicians of the World, Unite! [9].
}

the second or third choice for the position. In the end, he was not chosen as president, although it is interesting to note that the choice was William Granville, another mathematician and the author of one of the most influential calculus texts of the first half of the twentieth century [17], along with the book The Fourth Dimension and the Bible [18]. Eisenhart continued to serve as a trustee of the college until 1916 and received honorary degrees in both 1921 and 1926.

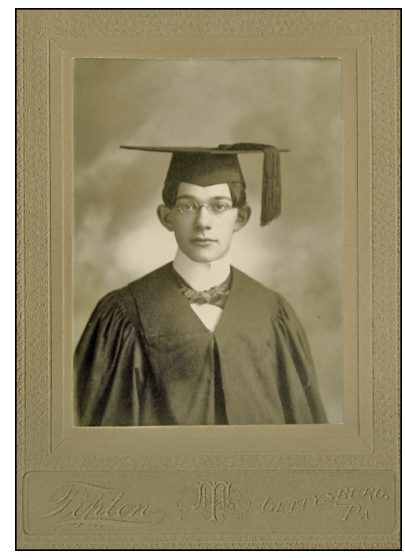

Eisenhart also received de- Pennsylvania College grees from Columbia, Lehigh, student.

Duke, Princeton, Johns Hopkins, and the University of Pennsylvania. In 1937 he was named Officer of the Order of the Crown of Belgium by King Leopold III. In 1945 Luther Eisenhart retired from Princeton University, although he did not lead the stereotypical life of leisure. He continued to be a prolific scholar, publishing nearly thirty additional papers, including a series of papers on "A unified theory of general relativity of gravitation and electromagnetism". He also remained active in professional societies, and the American Philosophical Society chose him to be their executive director, a post that he held until 1959. He died on October 28, 1965, at which time several of his faculty colleagues wrote of him that "in two centuries of Princeton's history few scholars did more to shape the future of the University."

\section{Coble}

Arthur Byron Coble was born on November 3, 1878, in Williamstown, Pennsylvania, a small town not far from Harrisburg. His father, Reuben Coble, had served in the Civil War in the 107th Regiment of the Pennsylvania Company and worked in manufacturing along with being a general store owner. Later in life, Reuben became the president of a small bank as well as one of the founders of The Lykens Pa Knitting \& Manufacturing Company, which made hosiery undergarments. Reuben married Emma Heagy from New Oxford, Pennsylvania, and the two of them had six children together, of whom Arthur was the third.

Arthur Coble arrived at Pennsylvania College in the fall of 1893 and roomed with his older brother, Charles Ray Coble, in a room near that of Luther Eisenhart in Pennsylvania Hall. Coble was not as much of a standout student as Eisenhart. He did not win any awards during his time at the college. When the Baum Prize was awarded to the sophomore student who was most proficient in mathematics, he was neither the winner nor among the six 
students listed as receiving honorable mention. He was, however, voted the secretary of his class as well as a member of the Philomathean Literary Society, the Debating Club, the Star Boarding Club, and an organization known as "Snake and Coffin". In the 1897 edition of the college's yearbook, The Spectrum, he listed his ambition upon graduation as "To Look Neat", while his want was "To Please Papa". Upon graduation, Coble returned to his hometown of Lykens, where he taught in the public schools for a year. In 1897 he applied to the doctoral program at Johns Hopkins, and his former professor Nixon wrote a letter on his behalf, saying that "Mr. Coble took great interest in his work. His natural ability and training recommend him to an unusual degree." He was admitted to the program and began classes in the fall of 1898, many of which he took alongside his former classmate, Luther Eisenhart. His studies at Hopkins culminated in his 1902 thesis written under Frank Morley, entitled "The Relation of the Quartic Curve to Conics", which he later published as an article in the Transactions of the American Mathematical Society [7].

After receiving his Ph.D., Coble spent a year teaching at the University of Missouri before returning to Johns Hopkins to continue his work with Morley. This research position was funded in part by the Carnegie Institution of Washington, which had recently been founded by Andrew Carnegie to fund scientific endeavors. Coble used the funding in part to travel to Germany, where he studied at Griefswald and Bonn with the invariant theorist Eduard Study. Coble taught at Johns Hopkins until 1918, when he accepted a full professorship at the University of Illinois Urbana-Champaign.

Coble continued his research in algebraic geometry and, in particular, on the Cremona group defined as the set of automorphisms of the field $k\left(x_{1}, \ldots, x_{n}\right)$ consisting of rational functions on $n$ variables. Even the case where $n=2$ is complicated, and Coble tried to understand what happens for larger $n$. Some of Coble's original work in the area uses invariant theory to solve general quintic and sextic equations by thinking of the Galois group of the equation as a group of Cremona transformations. As his work evolved, he was one of the first to use finite geometries to provide explicit equations for the famous " 27 lines on a cubic" problem. Much of his later work involved showing connections between the appearance of zero-cycles in the theory of modular forms and the zero-cycles that arise in the study of the Cremona group. During his career Coble published twenty papers in algebraic geometry and had thirty students receive Ph.D.'s under his direction, although Halmos writes that he could have had many more:
There is a story about him as a Ph.D. supervisor that may be apocryphal but is true in spirit. Allegedly he had an infinite sequence of Ph.D. thesis topics. Having proved a theorem in dimension 2, he had his next Ph.D. student extend the result to 3 , and the one after that to 4 . The story has it that Gerald Huff was the spoilsport; he settled not only 5 but every greater dimension too, and thus put an infinite number of prospective Ph.D.'s out of business. [20]

In 1893 the American Mathematical Society had started a series of meetings where prominent mathematicians were invited to give a series of talks on the topic of their choosing, which would then be written up and published as part of the Colloquium Publications series. The list of speakers reads like a who's who of American mathematicians from the early twentieth century, featuring names such as Bell, Dickson, Evans, Moore, and Veblen. Both Coble and Eisenhart were featured in the series. Eisenhart's lectures on non-Riemannian geometry were delivered at the Ithaca meetings in September 1925 and formed the basis for [12]. Coble's series of lectures, entitled "The determination of the tritangent planes of the space sextic of genus four", were delivered at the Amherst meeting in September 1928. It is interesting to note that only seventy-seven mathematicians were in attendance at Coble's talks, according to a report in the Bulletin of the AMS, compared to the national AMS meetings today, which draw upwards of 7,000 mathematicians. Coble's lectures were published as volume 10 of the AMS Colloquium Publications series in 1928 under the title Algebraic Geometry and Theta Functions [8], a book that has become a standard in the field. Upon its release, Zariski wrote very highly of Coble's book: “The principal merit of Coble's new volume [is] the geometric spirit, which seeks to discover the geometric reality hidden behind the formal properties of the functions $\theta$. The picture of this geometric reality, which the author draws before our eyes, is as varied as it is colorful...Coble's work is a really important contribution to the theory and application of the $\theta$-functions, and will be well accepted by competent readers" [29]. Both volumes from the AMS Colloquium Publications series have been republished many times, most recently in 2008.

Many objects in algebraic geometry are associated with Coble's name due to his work on them. A Coble curve is an irreducible degree 6 planar curve with ten double points. Various embeddings of Jacobians into projective space under thetamappings, which can be represented as singular 
loci of hypersurfaces, are given the name Coble hypersurfaces. More recently, Dolgachev and Zhang have defined the notion of a Coble surface to be a nonsingular projective rational surface $X$ with empty anticanonical linear system but nonempty antibicanonical system [10]. Coble was also an editor of many journals. At various points, he was an editor of Transactions of the American Mathematical Society and American Journal of Mathematics. He was also one of the founding editors of the Duke Mathematical Journal in 1935.

By all indications, Coble's preferred use of time was to do mathematics, but he had other interests as well. When asked by a colleague what he did for pleasure, he responded, "With respect to my hobbies, I can only say that they are essentially of a rather frivolous and time-consuming character. I enjoy out-of-door sports-golf, tennis, swimming, and walking, and in bad weather I turn to bridge and billiards and light reading."

Arthur Coble was not as enthusiastic in his embrace of administrative work as Luther Eisenhart had been. When the Urbana Faculty Senate published a tribute to him upon his passing, they wrote that "although he had little inclination for administrative responsibilities, he came to accept them as a necessary component of his work...He brought to these committees the calm judgment and the methodical analysis that characterized his work in other areas" [23]. Despite his aversion to administrative duties, he served as the head of the Department of Mathematics at the University of Illinois from 1934 until his retirement in 1947. During this time the department saw tremendous growth, with the graduate program in particular more than tripling in size. He also succeeded in hiring a number of prominent mathematicians to the faculty, two of whom, Joseph Doob and Oscar Zariski, would go on to also become presidents of the AMS. During Coble's time the University of Illinois was also known as a place particularly friendly to women in mathematics. It was one of the only universities with more than one woman on its faculty, and it graduated a relatively large number of women with Ph.D.'s in mathematics. Coble alone supervised five women in doctoral degrees.

There are very few records of Arthur Coble staying connected to Gettysburg College after his graduation. Several alumni magazines list him as donating money to the college, but most reports of reunions of the Class of 1897 specify that Arthur Coble could not attend due to professional obligations. One exception is the class's fiftieth reunion in 1947, which was celebrated at the Hotel Gettysburg with a dinner that Coble attended. In 1933 Coble was awarded an honorary degree of Doctor of Laws by the college.
Arthur Coble retired from the University of Illinois in 1947 and returned to his home state of Pennsylvania. This was likely due in part to his increasing symptoms from Parkinson's disease. Following his mentor Morley's lead, he accepted a position at Haverford College but was able to teach there for only one semester before his symptoms got bad enough that he was forced to retire for good. In 1956 he was involved in a car accident that left him unable to walk, and he

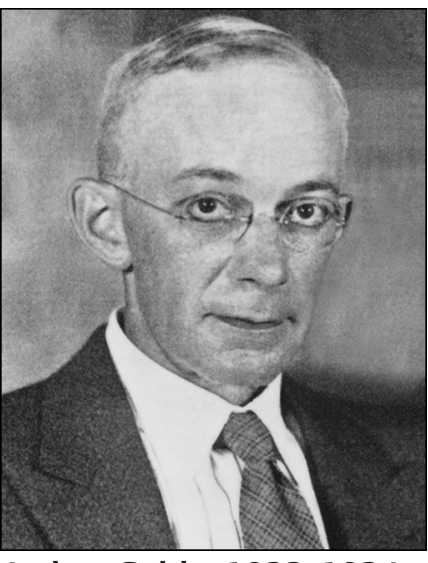

Arthur Coble, 1933-1934, AMS president. lived the rest of his life at the Lykens Hotel in his hometown. He died on December 15, 1966, in a Harrisburg hospital.

\section{Conclusion}

The lives of Luther Eisenhart and Arthur Coble were different in many ways, but both did great work. Eisenhart pursued a wide range of professional interests, ranging from writing textbooks to overhauling the curriculum at a major university. Coble, on the other hand, chose to focus on the mathematical problems that interested him in algebraic geometry, making him a leader in that field. Despite their differences, their paths crossed in a number of ways, not the least of which is that their academic careers began under similar circumstances, as both grew up in central Pennsylvania, graduated from Gettysburg College, and received doctorates from Johns Hopkins, where they took classes together. A couple of decades later they were coeditors of the Transactions of the American Mathematical Society, and they both served the Society in a number of different capacities. Both were undoubtedly leaders of the mathematical world, but they chose to express this in different ways. It is an interesting comment on the mathematical community in the 1930s that both approaches to one's career were rewarded and that both men could be elected president of the American Mathematical Society, one of the highest offices the profession has to offer.

\section{References}

1. Fifty-ninth Annual Catalogue of the Officers and Students of Pennsylvania College, http://www . archive. org/detai1s/gettysburgco11eg9899gett.

2. The Princeton Mathematics Community in the 1930s: An Oral History Project, http://www.princeton. edu/mudd/finding_aids/mathora1/pm02.htm

3. Sixty-third Annual Catalogue of the Officers and Students of Pennsylvania College, http://www. archive.org/detai1s/gettysburgcol1eg9899gett 
4. Twenty-second Annual Catalogue of Swarthmore College, http://www.archive.org/detai1s/ annua7catalogueo1890swar.

5. RAYMOND ClARE ARCHIBALD, American Mathematical Society Semicentennial Publications. Vol. I, American Mathematical Society, Providence, RI, 1988. A semicentennial history of the American Mathematical Society. 1888-1938. With biographies and bibliographies of the past presidents. Reprint of the 1938 original. MR 959537 (89i:01137)

6. Steve Batterson, Pursuit of Genius, A K Peters Ltd., Wellesley, MA, 2006. Flexner, Einstein, and the early faculty at the Institute for Advanced Study. MR 2248799 (2007f:01012)

7. A. B. Coble, The quartic curve as related to conics, Trans. Amer. Math. Soc. 4 (1903), no. 1, 65-85. MR 1500625

8. __ Algebraic Geometry and Theta Functions, American Mathematical Society Colloquium Publications, vol. 10, American Mathematical Society, Providence, RI, 1982. Reprint of the 1929 edition. MR 733252 (84m:14001)

9. GUILlERMO P. CURBERA, Mathematicians of the World, Unite!, A K Peters Ltd., Wellesley, MA, 2009. The International Congress of Mathematicians-A human endeavor. With a foreword by Lennart Carleson. MR 2499757 (2010a:01004)

10. IGOR V. DOLGACHEV and De-QI ZHANG, Coble rational surfaces, Amer. J. Math. 123 (2001), no. 1, 79-114. MR 1827278 (2002e:14061)

11. Luther PfAHLER EISEnHART, Continuous Groups of Transformations, Dover Publications Inc., New York, 1961. MR 0124008 (23 \#A1328)

12. __ Non-Riemannian Geometry, American Mathematical Society Colloquium Publications, vol. 8, American Mathematical Society, Providence, RI, 1990. Reprint of the 1927 original. MR 1466961 (98j:53001)

13. __ Riemannian Geometry, Princeton Landmarks in Mathematics, Princeton University Press, Princeton, NJ, 1997. Eighth printing, Princeton Paperbacks. MR 1487892 (98h:53001)

14. __ An Introduction to Differential Geometry, Princeton Mathematical Series, vol. 3, Princeton University Press, Princeton, NJ, 1940. MR 0003048 (2,154e)

15. JoHn GIBSON, History of York County Pennsylvania from the Earliest Time to the Present, FA Battey Publishing Company, Chicago, 1886.

16. ChARLES GLATFELTER, A Salutary Influence: Gettysburg College 1832-1985, W \& M Printing, Mechanicsburg, PA, 1987.

17. W. A. GRANVILLE, Elements of the Differential and Integral Calculus, Percey F. Smith, ed., Ginn \& Co., Oxford, UK, 1904 (revised 1911).

18. , The Fourth Dimension and the Bible, University Microfilms International, 1977.

19. W. C. GRAustein, Book Review: Transformations of Surfaces, Bull. Amer. Math. Soc. 30 (1924), no. 8, 454460. MR 1560939

20. PAUl R. HAlmos, I Want to Be a Mathematician, MAA Spectrum, Mathematical Association of America, Washington, DC, 1985. An automathography in three parts. MR 961440 (89e:01044)

21. Solomon Lefschetz, Luther Pfahler Eisenhart. January 13, 1876-October 28, 1965, Biograph. Mem. Nat. Acad. Sci. 40 (1969), 69-90.
22. A. Leitch, A Princeton Companion, Princeton University Press, 1978.

23. Arthur Mattuck, Arthur Byron Coble, Bull. Amer. Math. Soc.. 76 (1970), 693-699. MR 0255357 (41 \#19)

24. H. B. NIXON and J. C. FIELDS, Bibliography of Linear Differential Equations, Amer. J. Math. 7 (1885), no. 4, 353-363. MR 1505397

25. Karen Hunger PARshall and David E. Rowe, The Emergence of the American Mathematical Research Community, 1876-1900: J. J. Sylvester, Felix Klein, and E. H. Moore, History of Mathematics, vol. 8, American Mathematical Society, Providence, RI, 1994. MR 1290994 (95j:01032)

26. David Eugene Smith and Jekuthiel Ginsburg, $A$ History of Mathematics in America before 1900, Arno Press, New York, 1980. Reprint of the 1934 original, Three Centuries of Science in America. MR 749578 (85i:01018)

27. G. G. SzPIRo, Numbers Rule: The Vexing Mathematics of Democracy, from Plato to the Present, Princeton University Press, 2010.

28. Williams College, Catalogue, 1890.

29. OSCAR ZARISKI, Book Review: Algebraic Geometry and Theta Functions, Bull. Amer. Math. Soc. 36 (1930), no. 7, 452-454. MR 1561969

Editor's Note: The images of Luther Eisenhart (1931-1932) and Arthur Coble (1933-1934) are courtesy of the AMS archives. All other images in the article are courtesy of Special Collections/Musselman Library, Gettysburg College, Gettysburg, PA. 